\title{
PEDAGOGía dE OTROS SISTEMAS SIMBólICOS: Una aproximación al marco teórico 1
}

\author{
María del Pilar Vargas Daza² \\ Universidad Santo Tomás - Bucaramanga
}

\section{Resumen}

Este artículo presenta una aproximación al marco teórico para abordar las prácticas e interpretación de otros sistemas simbólicos en clases de lengua castellana. Las actividades lingüísticas sobrepasan campos específicos del área Lengua Castellana y son esenciales en las actividades curriculares de los estudiantes. Así, el lenguaje se constituye en una "herramienta cognitiva" que brinda al educando la posibilidad de ser sujeto activo en procesos de construcción de su propio conocimiento y se constituye en un elemento básico para aprendizajes que tendrán cabida a lo largo de su vida y que llevarán al estudiante a aproximarse y apropiarse de su realidad, configurarla, conservarla, reproducirla y/o manifestarla cuando se desee o se requiera. Es innegable que el hábitat comunicativo se ha centrado cada vez más en otros sistemas simbólicos debido al bombardeo de información desplegado en los medios de comunicación y a la sobre-exposición del estudiante a ellos. Esta abundancia de imágenes requiere un arduo trabajo de acompañamiento para la lectura de otros sistemas de comunicación no verbal que debe ser liderada por los maestros.

\section{Palabras clave}

Sistemas simbólicos, Imagen, Lectura, Interpretación.

\section{PEDAGOGY OF OTHER SYMBOLIC SYSTEMS: AN APPROAGH TO THE THEORETICAL FRAMEWORK}

\section{Abstract}

This article presents an approach to the conceptual framework for addressing practices and interpretation of other kinds of symbolic systems in Spanish. The language activities in the area go beyond specific fields of Spanish Language and are essential for curricular activities of students. Thus, language constitutes a "cognitive tool" which gives the learners the opportunity to be a participant in the process of constructing their own knowledge and constitutes a basic element of learning that will fit over the students' lives and will be an important element of their way to keep, reproduce and / or manifest reality when desired or required. It is impossible to deny that communication is focusing increasingly on other symbolic systems due to the amount of information displayed in the media and the student's exposure to them. This abundance of images requires a hard training to the reading of other nonverbal communication systems that must be led by teachers.

\section{Kev words}

Symbolic systems, Image, Reading, Interpretation.

1 Artículo corto, producto del proceso de investigación en "Prácticas de comprensión e interpretación de otros sistemas simbólicos en clase de lengua castellana, en la básica secundaria y media", para optar al el título de Magíster en Pedagogía de la Universidad Industrial de Santander.

2 Docente Instituto de Lenguas, Universidad Santo Tomás, Asesora pedagógica y Profesional de Apoyo CEE, Universidad Santo Tomás, Licenciada en Idiomas, Universidad Industrial de Santander, Especialista en Literatura Hispanoamericana, crítica y docencia. Universidad Santo Tomás, Especialista en Docencia Universitaria. Universidad Santo Tomás, Magíster en Pedagogía, Universidad Industrial de Santander, Supervisora de Prácticas Docentes de la Licenciatura en Español y Literatura, Universidad Industrial de Santander. pilarvargas74@yahoo.com 


\section{Introducción}

Acercarse a la realidad educativa colombiana es un primer paso para fundamentar el trabajo pedagógico basado en la generación de experiencias significativas para la exploración y uso de las diferentes manifestaciones de lenguaje verbal y no verbal. Para el propósito de la investigación educativa el escenario apropiado es el aula, considerándola según los Lineamientos Curriculares de Lengua Castellana como

"un espacio de construcción de significados y sentidos, y como una micro sociedad en la que se tejen relaciones sociales (...); un espacio de argumentación en el que se intercambian discursos, comunicaciones, valoraciones éticas y estéticas." ${ }^{3}$

En otras palabras, se requiere que los docentes en ejercicio mantengan un hilo conductor que interrelacione los saberes pedagógicos con el saber-ser y el saber-hacer. De aquí parte la necesidad de observar procesos educativos reales como las interacciones entre educandos, educadores, mediaciones didácticas, enmarcadas en un ámbito institucional real con el fin de empezar a cuestionarse si la interacción educativa en espacios y tiempos reales está efectivamente basada en lo propuesto en los Lineamientos y Estándares Básicos de la Lengua Castellana.

Lo descrito en líneas anteriores es precisamente el punto de inicio del proyecto de investigación "Prácticas de comprensión e interpretación de otros sistemas simbólicos en clase de lengua castellana, en la básica secundaria y media", trabajo que se desarrolla dentro del marco del enfoque cualitativo bajo el modelo etnográfico y busca determinar las diversas formas de abordar e interpretar otros sistemas simbólicos en las clases de

3 Lineamientos Curriculares para la Lengua Castellana. Serie Lineamientos Curriculares. Ministerios de Educación Nacional. Bogotá. Pág. 35. lengua castellana en un colegio del sector público del área urbana de Bucaramanga. El proyecto se encuentra en desarrollo y se sustentará como requisito para aspirar al grado de Magíster en Pedagogía.

El presente artículo pretende mostrar una aproximación teórica de la investigación sobre elementos teóricos fundamentales que deben considerarse antes de "un espacio de construcción de significados $y$ sentidos, y como una micro sociedad en la que se tejen relaciones sociales (...); un espacio de argumentación en el que se intercambian discursos, comunicaciones, valoraciones éticas y estéticas." reflexionar sobre el uso y la exploración de las diferentes manifestaciones de otros sistemas simbólicos en las instituciones educativas, al traspasar la teoría que se establece desde los lineamientos establecidos por el Ministerio de Educación Nacional y dar un paso adentro de las aulas, es decir, al vivir la 'realidad' educativa colombiana.

\section{Horizonte Teórico}

La lengua y el uso de la misma han ocupado un lugar preponderante en la historia de la humanidad. Desde el pasado y en la actualidad, ha sido objeto de estudios y análisis no sólo en los aspectos formales del sistema lingüístico sino también aquellas cosas que las personas hacemos con las palabras. Por esto, se han abordado variados estudios desde diferentes perspectivas, enfoques y disciplinas que han coincidido con el interés por estudiar y conocer el uso lingüístico de las personas en contextos reales de producción y recepción. Con base en lo anterior, es necesario considerar ciertos términos y autores específicos que orientan el desarrollo de este proyecto. 


\section{1 Pedagogía y didáctica}

Según Francisco Díaz en su texto “Didáctica y Currículo: un enfoque constructivista", hablar de didáctica es referirse a una

“disciplina pedagógica que analiza, comprende y mejora los procesos de enseñanza-aprendizaje, las acciones formativas del profesorado y el conjunto de interacciones que se generan en la tarea educativa. El objeto prioritario de estudio de la didáctica es la enseñanza, en cuanto propicia el aprendizaje formativo de los estudiantes, la selección de las materias o contenidos más valiosos y la proyección que tal enseñanza tiene en la formación profesional"4.

Por tanto, se puede decir que la didáctica se ocupa de la enseñanza, del aprendizaje y de formar integralmente al discente. Sin embargo, en la actualidad no sólo se habla de una Didáctica Magna, como lo enmarcaba Comenio, pues sería muy difícil pensar una didáctica que pudiera compactar sus teorías y las de otros pedagogos; se clama por una didáctica propia de cada ciencia y se han desarrollado procesos que han llevado a la construcción de propuestas de enseñan$z a$, las cuales, de una forma u otra han sido elementos constitutivos de marcos teóricos de referencia para el quehacer docente de cada disciplina. Debido a lo anterior $y$, a partir de las concepciones generales del término "didáctica", se han aunado estudios e investigaciones que intentan traspasar los libros de texto de Lengua Castellana para llegar a aspectos pedagógicos y conformar la “Didáctica de la Lengua" como

"una disciplina que necesita autodefinirse en su naturaleza, en sus niveles y en sus objetivos para conseguir identificarla como disciplina diferenciada

4 DÍAZ, Francisco. "Didáctica y Currículo: Un enfoque constructivista". Ediciones de la universidad de Castilla. La Mancha, 2002. Pág. 35 y no como un mero apéndice de otras disciplinas con solera de muchos años de existencia"t".

Por consiguiente, la educación en las aulas de enseñanza en la básica secundaria y media vocacional no sólo debe considerar el conocimiento formal de las teorías del lenguaje sino también el uso comunicativo que las personas inmersas en una sociedad hacen de ellas. De ahí que ya no sólo basta con la enseñanza del "saber lingüístico" sino que se hace imperiosa la necesidad de ayudar a los estudiantes a construir el mayor grado de competencia comunicativa, es decir, guiar a los alumnos y a las alumnas a que adquieran la "capacidad para comprender y producir enunciados adecuados a sus intenciones diversas de comunicación en contextos comunicativos y heterogéneos" ${ }^{\prime \prime}$. Para el caso particular de la Lengua Castellana, se han propuesto

5 MILLÁN, Alberto. “Estudios de didáctica de lengua española para universitarios". Ediciones Universidad de Sevilla. Sevilla, 1991. Pág. 11.

6 LOMAS, Carlos. "Cómo enseñar a hacer cosas con las palabras". Volumen 1. Editorial Paidós. Barcelona, 1999. Pág. 35 


\begin{tabular}{c} 
"hombres y \\
mujeres capaces \\
de conceptualizar \\
la realidad, de \\
comprenderla e \\
interpretarla, de \\
comunicarse e \\
interactuar con \\
sus congéneres y \\
de participar de \\
la construcción de \\
un país solidario, \\
tolerante y \\
diverso en el que \\
quepan todos, \\
sin distingos ni \\
exclusiones" \\
\hline
\end{tabular}

diversos caminos para orientar la formación en lenguaje. Según las metas esbozadas en las líneas de documentos oficiales del Ministerio de Educación tales como los Lineamientos Curriculares y los Estándares Básicos de Competencias del Lenguaje, formar en lenguaje es un reto que debe apuntar a desarrollar competencias con el fin de tomar participación activa en situaciones comunicativas reales, habida cuenta que dichas competencias suponen el manejo de unos saberes referidos a sistemas lingüísticos, producción y comprensión textual y adopción de posturas frente a diferentes tipos de discursos, entre otros. Así, los maestros en ejercicio deben asumir en sus prácticas pedagógicas, elementos que ayuden a formar a

"hombres y mujeres capaces de conceptualizar la realidad, de comprenderla e interpretarla, de comunicarse e interactuar con sus congéneres $y$ de participar de la construcción de un país solidario, tolerante y diverso en el que quepan todos, sin distingos ni exclusiones"

Parafraseando a Alfonso Vargas $^{8}$, se aporta a la construcción de pactos de convivencia y respeto como alternativa al creciente deterioro de la calidad de vida

\footnotetext{
7 Ibíd. P. 23.

8 VARGAS, A. (2004) "Estándares y ética de la comunicación". En En Redate Vé. Boletín No. 7. Enero de 2004. Universidad del Valle- Red de Maestros del Valle del Cauca para la Transformación de la Cultura Escolar desde el Lenguaje. Cali.
}

de las personas. Para esto, los Estándares Básicos de Competencias del Lenguaje hacen referencia a tres campos fundamentales en los que nuestros maestros de lengua castellana deben estar muy bien fundamentados ya que suponen

“la formación en lenguaje para la educación básica y media: pedagogía de la lengua castellana, pedagogía de la literatura y pedagogía de otros sistemas simbólicos". ${ }^{9}$

El primer campo, pedagogía de la lengua castellana, centra su atención en desarrollar la competencia comunicativa de los educandos con el fin de prepararlos para actuar e interactuar desde el lenguaje con los demás en los diferentes contextos que ellos requieran. En este primer campo los docentes deben separarse de enfoques de corte "estructural, normativo y formalista" para así dar paso a incentivar la potenciación de comprensión y producción discursivas.

El segundo campo, la pedagogía de la literatura, busca específicamente despertar el gusto por la lectura, además de establecer una tradición lectora que genere procesos sistemáticos tendientes a fortalecer su dimensión humana y su concepción e interpretación de mundo. En este campo se plantea el goce literario como "objeto de comunicación pedagógica" para preparar lectores críticos de su propia cultura y despertar su sensibilidad ante el lenguaje poético. Por otra parte, el papel de docente no es sólo escoger las lecturas apropiadas para cada grado, sino también proponer estrategias que favorezcan el desarrollo de procesos psicológicos superiores tales como el pensamiento, la creatividad y la imaginación.

Sin embargo, no sólo los textos verbales son importantes en la enseñanza del lenguaje. Es necesario conocer otros sistemas que permiten al individuo expresarse

9 "Estándares Básicos de Competencias del Lenguaje". Ministerio de Educación Nacional. Bogotá, P. 24. 
e interactuar con los otros seres; es el tercer campo mencionado en los Estándares, el campo de la pedagogía de otros sistemas simbólicos ${ }^{10}$. En este campo se trabaja la comprensión y producción de aspectos no verbales: proxémicos (manejo de espacio con intenciones significativas); kinésicos (lenguaje corporal); prosódicos (significados de entonaciones, pausas, y otros.). Estos aspectos no verbales conforman procesos comunicativos y lingüísticos que inciden en aspectos culturales, ideológicos y sociales. De hecho, según Carlos Lomas en su texto "Cómo enseñar a hacer cosas con las palabras", dichos aspectos hacen parte de la competencia semiológica. Esta competencia es entendida como

"la adquisición de los conocimientos, habilidades y actitudes que hacen posible una interpretación crítica de los usos y formas icono verbales de los mensajes de los medios de comunicación de masas y de la publicidad"11.

Entonces, desde nuestra posición como docentes, se convierte en una de nuestras tareas no sólo concentrarnos en la enseñanza de los aspectos formales de la lengua, sino también contribuir desde una posición de reflexión semiológica en torno a materiales iconográficos.

\subsection{Competencia}

Los Lineamientos Curriculares para la Lengua Castellana, documento emitido por el Ministerio de Educación Nacional, han señalado algunas limitaciones del modelo curricular que se basaba en la tecnología educativa, entre otras: la rigidez del currículo y de los formatos de planeación así como la no participación de los docentes en la elaboración de los mismos. Ante estas falencias el MEN ha trabajado en el desarrollo de competencias como eje del desarrollo curricular. Esta noción

\footnotetext{
10 Ibíd. P. 26.

11 LOMAS, C (1999). “Cómo enseñar a hacer cosas con las palabras". Volumen 1. Editorial Paidós. Barcelona. P. 159.
}

de competencia ha sido pensada desde

“la constitución y formación de los sujetos en diferentes dimensiones de su desarrollo. Pero esta noción está referida básicamente a potencialidades $\mathrm{y} / \mathrm{o}$ capacidades. Las competencias se definen en términos de 'las capacida"la adquisición de los conocimientos, habilidades $y$ actitudes que hacen posible una interpretación crítica de los usos y formas icono verbales de los mensajes de los medios de comunicación de masas y de la publicidad" des con que un sujeto cuenta para (...)'. Pero es claro que estas competencias, o más bien el nivel de desarrollo de las mismas, sólo se visualiza a través de desempeños, de acciones, sea en el campo social, cognitivo, cultural, estético o físico"12.

De acuerdo a lo anterior, la formación en competencias constituye el referente para visualizar que las propuestas curriculares sean alrededor de proyectos pedagógicos orientados hacia la significación y la comunicación organizados para propiciar la "construcción colectiva e interactiva de los saberes".

Algunas de las competencias que el MEN asocia en su documento de Lineamientos Curriculares para Lenguas Castellana son: ${ }^{13}$

- Gramatical o sintáctica para producir enunciados lingüísticos.

- Textual que garantice coherencia y cohesión.

- Semántica para reconocer y usar significados y léxico de manera pertinente de acuerdo al contexto de la comunicación.

\footnotetext{
12 “Lengua Castellana. Lineamientos Curriculares". Ministerio de Educación Nacional. Editorial Delfín. Bogotá. P. 34.

13 lbíd. P 51
} 
- Pragmática o socio-cultural sobre el reconocimiento y uso de las reglas contextuales de la comunicación.

Enciclopédica para poner en juego los saberes con los que cuentan los sujetos.

Literaria, entendida como la capacidad de poner en juego procesos de lectura y escritura.

Poética, entendida como la capacidad de un sujeto para inventar mundos posibles a través de los lenguajes e innovar en los mismos.

Esta preocupación de las políticas nacionales de la educación por nuevas propuestas curriculares que giren en función a las habilidades comunicativas y a competencias asociadas con la significación y la comunicación, servirán para orientar nuestro trabajo en cuanto al papel que los docentes desarrollan bajo las directrices de estos lineamientos en lengua castellana. Es decir, podremos analizar las acciones pedagógicas cotidianas para generar procesos de comunicación y significación, en nuestro caso particular, en torno a 'otros sistemas simbólicos'.

\subsection{Competencia comunicativa}

Si partimos de la necesidad de orientar la enseñanza de la lengua castellana para favorecer el desarrollo de habilidades comunicativas, no es posible enfocarse solamente en el aprendizaje del saber lingüístico pues esto no garantizaría que se mejoraran las capacidades de las personas para comprender y expresarse. Entonces, la asignatura de lengua castellana debería contribuir a ayudar a los estudiantes a mejorar su competencia comunicativa en los diferentes contextos de comunicación.

Desde la etnografía de la comunicación, la competencia comunicativa es

"ese conjunto de conocimientos y habilidades que se van adquiriendo a lo largo del proceso de socialización de las personas (dentro y fuera de la escuela) y por lo tanto, está socioculturalmente condicionada". ${ }^{14}$

Aprender a hablar no sólo es usar la estructura formal de la lengua sino también aprender a usar los registros de acuerdo a la situación y los interlocutores, los fines, el tono y el género discursivo, sin olvidar ciertas normas que deben considerarse según la situación comunicativa.

Según Hymes, la adquisición de la competencia comunicativa se alcanza cuando se usan apropiadamente ciertos conocimientos, normas y destrezas de una forma correcta y adecuada al contexto o situación comunicativa. Es decir, la competencia comunicativa está integrada por las siguientes (sub)competencias ${ }^{15}$ :

a. Lingüística, entendida a la vez como capacidad innata para hablar una lengua y como conocimiento de la gramática de esa lengua;

b. Sociolingüística, referida al conocimiento de las normas socioculturales que regulan un comportamiento comunicativo adecuado en los diferentes ámbitos del uso lingüístico;

c. Discursiva o textual, relativa a los conocimientos y habilidades que se precisan para comprender y producir diferentes tipos de discurso con arreglo a los principios de cohesión y coherencia;

d. Estratégica, que se refiere al dominio de los recursos que podemos utilizar para resolver los diversos problemas que se pueden producir en el intercambio comunicativo.

Carlos Lomas en su texto "Cómo enseñar a hacer cosas con las palabras". Vol. I, añade otros dos tipos específicos de

14 LOMAS, C. (1999) Cómo enseñar a hacer cosas con las palabras. Volumen 1. Editorial Paidós. Barcelona. P. 32.

15 Ibíd., P. 159. 
competencias que tienen una especial significación pedagógica: la competencia literaria que incluye conocimientos, las habilidades y hábitos que posibilitan el uso y el disfrute de los textos literarios. Según Lomas, adquirir y desarrollar esta competencia es un proceso largo que involucra aspectos cognoscitivos, éticos, éticos, lingüísticos y culturales que se desarrollan durante la educación básica, secundaria y media. La otra competencia que se enuncia es la competencia semiológica, la cual incluye los conocimientos, las habilidades y las actitudes que favorecen una interpretación crítica de los usos y formas de los medios de comunicación de masas y de la publicidad. Lomas insiste en la urgente necesidad de contribuir desde la educación lingüística a la adquisición de esta competencia en torno a los mensajes icono-verbales de los medios de comunicación de masas y la publicidad.

\subsection{Lectura:}

Al observar las aulas de clase como escenarios comunicativos, es posible percibir cómo la lectura y la comprensión de textos se han constituido en las prácticas más habituales dentro de las actividades de enseñanza y aprendizaje. $Y$ es que cuando se enseña a leer y a comprender, no sólo se orienta esta actividad al aprendizaje de contenidos educativos sino que se dota al estudiante de una herramienta de comunicación entre las personas y la cultura. En otras palabras, para que el estudiante se 'apropie' de los contenidos escolares, es necesario que posea un conocimiento previo que le permita acceder a la información de los textos de cada una de las diferentes disciplinas del conocimiento. También requiere de habilidades de comprensión de textos que se presentan en nuestra vida cotidiana.

Sin embargo, es necesario contextualizar el papel de la lectura en las políticas nacionales de educación. Para esto, toma- remos los ejes alrededor de los cuales se piensan las propuestas curriculares desde los Lineamientos para la Lengua CasteIlana y ubicaremos el lugar que ocupa la lectura en alguno de estos ejes referidos a los procesos: 16

- de construcción de sistemas de significación

- de interpretación y producción de textos

- culturales y estéticos asociados al lenguaje: el papel de la literatura

- culturales implicados en la ética de la comunicación y a los principios de la interacción

- de desarrollo del pensamiento.

Si bien el primer eje es el referido al trabajo pedagógico de la construcción de diferentes formas a través de las cuales se construye la comunicación y se da la significación no sólo en textos verbales sino también en cuanto al conjunto de signos, lenguajes de la imagen, señales y demás, los lineamientos también aclaran que debido a la "importancia social y cognitiva, el énfasis del trabajo recae sobre el lenguaje verbal"17. Es esta otra razón de más para llevar a cabo el diagnóstico en las prácticas de comprensión e interpretación de otros sistemas simbólicos en clase de lengua castellana.

En cuanto a la lectura, los Lineamientos Curriculares retoman este concepto a partir del segundo eje referido a los procesos de interpretación y producción de textos (de lenguaje verbal), mas no enfatizan en la lectura de otros 'sistemas simbólicos'. Por lo tanto, partiremos de los documentos oficiales del MEN para revisar los conceptos de lectura que se manejan no sólo desde los Lineamientos sino también desde los Estándares Básicos de Competencias.

16 Lengua Castellana. Lineamientos Curriculares. Ministerio de Educación Nacional. Editorial Delfín. Bogotá. P. 53.

17 Op. Cit. P. 54 


\subsection{Otros Sistemas Simbólicos}

Carlos Lomas en su texto "El aprendizaje de la comunicación en las aulas", señala que

"Ios contenidos culturales que se transmiten a través de los distintos medios lel lienzo, el libro, el periódico, el filme, la radio, la televisión, el ordenador) se codifican en sistemas simbólicos. La apropiación de la materia, de la lógica y de las normas, de los mecanismos y de las técnicas de esos sistemas simbólicos, constituye la tarea más explícita y clásica de la alfabetización. El siglo que termina ha supuesto la irrupción de un conjunto poderoso de sistemas simbólicos no verbales o no predominantemente verbales" $"$.

El autor asegura que los medios y sistemas simbólicos han aceptado una lógica de concurrencia simultánea y utilización combinada. Es decir, aquello que hasta algún tiempo se consideraba como un único sistema lineal 'verbal', hoy día debe ceder terreno importante a modelos dialógicos de trabajo, a un gran número de textos y discursos y a diversos códigos tanto verbales como no verbales. En las palabras de Carlos Lomas sería: "De la lógica de la monodia debe pasar a la de la orquesta y la polifonía".

Pues bien, esta polifonía de sistemas simbólicos supone un cambio en el quehacer pedagógico. Por tanto, es necesario que revisemos cuál es la posición del MEN ante este fenómeno desde los Estándares Básicos de Competencias en lenguaje, documento oficial que sirve como guía sobre lo que los estudiantes deben saber y saber hacer con lo que aprenden. Según el documento formar en lenguaje

“implica avanzar también en el conocimiento de otros sistemas que le permitan al individuo expresar sus ideas,

18 LOMAS, C. (1999) El aprendizaje de la comunicación en las aulas. Ediciones Paidós, Ibérica, S.A. Barcelona. P. 321. deseos y sentimientos e interactuar con los otros seres de su entorno. Esto quiere decir que se hace necesario trabajar en la comprensión y producción de los distintos aspectos no verbales (...) que se deben abordar puesto que se emplean $y$ forman parte de las representaciones $y$ procesos comunicativos. Así, pues, se buscar desarrollar y potenciar la competencia simbólica de los y las estudiantes, con el fin que reconozcan las características y los usos de los sistemas no verbales $y$ el papel que estos juegan en los procesos lingüísticos"19.

Tal como se menciona en este documento oficial, la capacidad del lenguaje abre la posibilidad de conformar sistemas simbólicos que tienen que ver con lo verbal (para este caso lengua castellana) y lo no verbal (gestualidad, grafiti, cine y video,

19 Estándares Básicos de Competencias. Ministerio de Educación Nacional. Imprenta Nacional de Colombia. Bogotá, P. 26. 
entre otros). Es por esto que es necesario tomar los estándares y revisar de qué manera han sido estructurados desde los inicios de los años escolares. Para nuestro caso en particular, nos enfocaremos en uno de los cinco factores de organización: medios de comunicación y otros sistemas simbólicos, para lo cual parafrasearemos algunas líneas de la página 27 del documento y que se refieren específicamente a este factor: en los primeros grados se enfatiza en la aproximación creativa a diferentes códigos no verbales, con miras a la comprensión y recreación de estos en diversas circunstancias; grados más adelante los Estándares proponen que en cuanto a los lenguajes no verbales, se puede incrementar el acercamiento analítico a sistemas simbólicos diferentes a la lengua y la literatura, con miras a entender su funcionamiento comunicativo. Posteriormente, se puede hacer mayor énfasis en la comprensión de aspectos culturales y sociales que los fundamentan y después, se ampliará el trabajo en la dirección de encontrar opciones interpretativas que enriquezcan la capacidad crítica de los estudiantes.

\subsection{Semiótica de los mensajes visuales}

Umberto Eco en su libro "La estructura ausente. Introducción a la semiótica" dedica dos capítulos a interpretar las comunicaciones visuales bajo el punto de vista semiótico. En la sección B: La Mirada Discreta (Semiótica de los mensajes visuales) se afirma que los símbolos visuales forman parte de un 'lenguaje' codificado, pues en la medida que cualquier índice visual comunique algo por medio de un impulso, esto se debe a un sistema de convenciones o de experiencias aprendidas. En palabras de Eco

"se puede afirmar perfectamente que todos los fenómenos visuales que pueden ser interpretados como índi- ces también pueden ser considerados como signos convencionales" ${ }^{20}$.

Establece la siguiente clasificación ${ }^{21}$ que en el momento de describir los 'otros sistemas simbólicos' que se usan en las aulas de la institución serán de gran utilidad para hacer el análisis pertinente, códigos:

a. perceptivos

b. de reconocimiento

c. de transmisión

d. tonales

e. icónicos

1. Figuras

2. Signos

3. Enunciados icónicos o semas

f. iconográficos

g. del gusto y de la sensibilidad

h. retóricos

i. estilístico

j. del inconsciente.

En esta misma sección el semiólogo analiza elementos relacionados con signos icónicos de anuncios y mensajes publicitarios así como los dos registros sobre los cuales funcionan (verbal y visual) y su mecánica de la percepción que puede ser considerada como un acto de comunicación. Así mismo incluye un capítulo para el análisis del código cinematográfico, la imagen cinematográfica y el código fílmico. A su vez, hace análisis sobre carteles, fotografías, obras de arte, elementos que según los Estándares Básicos de Competencias en lenguaje deben trabajarse en los grados de básica secundaria y media.

20 ECO, U. (1981) La Estructura Ausente. Introducción a la semiótica. Editorial Lumen. Barcelona. P. 219.

21 Ibíd. P. 270 
Así mismo, la arquitectura como rasgo cultural y social en diversas manifestaciones del lenguaje no verbal, es uno de los subprocesos que el estudiante debe abordar en los grados de octavo a noveno. Para este aspecto encontramos la sección C: 'La función y el signo', pues como el mismo semiólogo Umberto Eco afirma:

"si la semiótica no es solamente la ciencia de los signos reconocidos en cuanto a tales, sino que se puede considerar igualmente como la ciencia que estudia todos los fenómenos culturales como si fueran sistemas de signos - partiendo de la hipótesis de que en realidad todos los fenómenos culturales son sistemas de signos, $o$ sea, que la cultura esencialmente es comunicación - uno de los sectores en que la semiótica encuentra mayores dificultades, por la índole de la realidad que pretende captar es el de la arquitectura"22.

En cuanto a este aspecto en la arquitectura se distinguen dos códigos: de lectura y de elaboración del proyecto. Para nuestro caso en particular nos centraremos en la manera de leer un objeto arquitectónico y no en la manera de leer un proyecto. Esto es, en las reglas de interpretación de un lenguaje no escrito, según modos convencionales de la escritura.

En este aspecto observaremos la forma en que los docentes llevan a los estudiantes a hacer análisis de signos icónicos, diagramas, indicios y símbolos, entre otros.

\subsection{Medios de comunicación de masas}

En el texto Apocalípticos e integrados del semiólogo italiano Umberto Eco, se analizan las diferentes actitudes que el mundo ha adoptado ante el universo de las comunicaciones de masas. A aque-

22 Op. Pág. 323. llas personas conservadoras que veían en el incremento de las masas al acceso de la cultura como una catástrofe y una destrucción de valores previamente establecidos por un número selecto $y$ reducido de personas, el autor los denomina apocalípticos. Por el contrario, quienes 'integraban' esta nueva cultura de masas y sobrevaloraban cualquier tipo de información transmitida por los medios de comunicación eran definidos por el autor como integrados.

Umberto Eco plantea puntos de vista a favor $y$ en contra no "si la semiótica no es solamente la

ciencia de los signos reconocidos en cuanto a tales, sino que se puede considerar igualmente como la ciencia que estudia todos los fenómenos culturales como si fueran sistemas de signos - partiendo de la hipótesis de que en realidad todos los fenómenos culturales son sistemas de signos, o sea, que la cultura esencialmente es comunicación - uno de los sectores en que la semiótica encuentra mayores dificultades, por la índole de la realidad que pretende captar es el de la sólo de estas posiciones extremistas sino también del rol que la educación ha tomado hasta el momento:

"los mass media se presentan como el instrumento educativo típico de una sociedad de fondo paternalista, superficialmente individualista y democrática, sustancialmente tendente a producir modelos humanos hetero-dirigidos (...). Adoptan las formas externas de una cultura popular, pero en lugar de 
surgir espontáneamente desde abajo, son impuestas desde arriba"23

Según el autor los problemas han sido mal planteados si se enuncian desde la siguiente perspectiva: '¿Es bueno o malo que exista la cultura de masas?'. El problema de los medios de comunicación de masas, según el autor, debería estar planteado de la siguiente manera: 'Desde el momento en que la presente situación de una sociedad industrial convierte en ineliminable aquel tipo de relación comunicativa conocido como conjunto de los medios de masa: ¿Qué acción cultural es posible para hacer que estos medios de masa puedan ser vehículo de valores culturales?

\subsection{Medios visuales}

Miguel Rojas Mix en su texto "El imaginario. Civilización y cultura del siglo XXI" propone abordar el análisis de la imagen desde el ángulo de la significación. Reflexiona sobre el imaginario de imagen y lo entiende como

"el encadenamiento de imágenes con vínculo temático o problemático recibidas a través de diversos medios audiovisuales, que el individuo interioriza como referente o el estudioso reconoce como conjunto" 24 .

Así mismo, el autor reconoce que en las últimas décadas del siglo $X X$ se ha pasado de una forma de conocimiento a otra: "transitamos de la civilización del texto leído a la civilización del texto visto" a lo cual no somos ajenos, pues la adquisición del conocimiento ahora se hace en su mayoría a través de la visión y de la escucha, sentidos que permiten la percepción de varias señales sin un orden estricto. Rojas Mix afirma que es necesario dejar de considerar la imagen como elemento de ilustración o como

23 ECO, U. (1993) Apocalípticos e integrados Editorial Lumen. Barcelona. P. 59

24 ROJAS, M. (2006) El imaginario. Civilización y Cultura del S. XXI. Prometeo Libros. Buenos Aires. P. 19. "el encadenamiento de imágenes

con vínculo temático o problemático

recibidas a través de diversos medios

audiovisuales, que el individuo

interioriza como referente o el

estudioso reconoce como conjunto"

auxiliar audiovisual. De hecho, insiste en que se le debe considerar como una "entidad autónoma con una intensidad propia", pues la imagen tiene la propiedad de condesar realidades sociales que pueden convertirse en un documento invaluable para estudiar épocas, hábitos y valores, entre otros.

Por otra parte, si se considera que hasta algún tiempo la información visual era sumamente restringida y accesible en reproducciones de libros o en visitas a museos o viajes culturales que no estaban al alcance de todas las personas, se notará que como afirma Miguel Rojas Mix, "con la revolución informática entramos en la civilización de la imagen". Las ciencias de la información y comunicación representan un cambio fundamental en nuestras culturas, lo cual se ve reflejado en aspectos sociales y pedagógicos. El bombardeo de información a que nos someten los medios electrónicos privilegia el hecho visual con el fin de transmitir información de manera instantánea. Esta velocidad vertiginosa impide en ocasiones que se llegue a reflexionar o mucho menos a hacer una crítica objetiva en cuanto a las imágenes que se perciben, lo cual podría poner en riesgo de ser manipulados por ellas.

Como afirma nuevamente Rojas Mix:

"La globalización es la cultura de la imagen, porque ella no se lee ni en inglés, ni en español, ni en chino, simplemente se ve. En realidad, civilización de la imagen, es aquella de la imagen mediática: invasora, 
omnipresente, que inunda nuestra vida cotidiana, que es sinónimo de televisión y publicidad"25.

Es posible observar cómo se asocian hábilmente la palabra y la imagen para crear sentido y además cómo funciona el discurso visual a través de la ilustración. Entonces, este autor nos permitirá acercarnos desde lo teórico para analizar otros sistemas simbólicos del lenguaje no verbal que en la actualidad inundan a nuestros estudiantes: la pintura, la escultura, mapas y planos, tarjetas postales, ilustraciones, carteles, propaganda y publicidad, fotografía, cómics, teatro, tatuajes, en fin, la industria cultural, la cultura de masas y la cultura popular que confluyen en un espacio reducido como lo es el aula de clase.

Esta es la aproximación al marco teórico del proyecto de investigación. En próximas ediciones se presentará la metodología, los hallazgos, las discusiones sustentadas y una bibliografía ampliada que será el resultado de este proceso investigativo.

\section{Referencias}

BARRAGÁN, Rafael. "Presencia de los lenguajes no verbales en el área de lengua castellana, en: Didáctica de la lengua materna - estado de la discusión en Colombia - (memorias del primer seminario y coloquio de didácticas de las lenguas y la literatura). Fernando Vásquez, ed., Cali, 2005.

COMITÉ ACADÉMICO DE LICENCIATURAS. Lineamientos para la Práctica Docente I y II de las Licenciaturas de la Universidad Industrial de Santander. año 2009

DÍAZ, Francisco. Didáctica y Currículo: Un enfoque constructivista. Ediciones de la universidad de Castilla. La Mancha, 2002.

ECO, Umberto. Apocalípticos e integrados. Editorial Lumen. Barcelona, 1993.

ECO, Umberto. La estructura ausente. Introducción a la semiótica. Editorial Lumen, Barcelona, 1981.

ECO, Umberto. Tratado de semiótica general. Editorial Lumen, Barcelona. Año 2000

FERRÉS, JOAN. Educar en una cultura del espectáculo. Editorial Paidós. España, 2000.

GOETZ, J.P. y M.D. LeCompte. Etnografía y diseño cualitativo en investigación educativa. Ediciones Morata. Madrid, 1998

LOMAS, Carlos. Cómo enseñar a hacer cosas con las palabras. Volúmenes y 2 . Editorial Paidós. Barcelona, 1999.

LOMAS, Carlos. El aprendizaje de la comunicación en las aulas. Ediciones Paidós, Ibérica, S.A. Barcelona.
MCKERNAN, James. Investigación-acción y currículum. Ediciones Morata. Madrid, 1999.

MILLÁN, Alberto. Estudios de didáctica de lengua española para universitarios. Ediciones Universidad de Sevilla. Sevilla, 1991.

MINISTERIO DE EDUCACIÓN NACIONAL. Lengua Castellana. Lineamientos Curriculares. Editorial Delfín. Bogotá. Año 1998

MINISTERIO DE EDUCACIÓN NACIONAL. Bogotá. Estándares Básicos de Competencias del Lenguaje Año 2006

ROJAS, Miguel. El imaginario. Civilización y cultura del siglo XXI. Prometeo Libros. Buenos Aires, 2006.

ROSALES, Horacio. Sentido común, colombianadas y conocimiento de la lengua, en: II Taller para la Transformación de la formación docente en lenguaje. Septiembre, 2008.

SANDOVAL, C. Carlos Arturo. Seminario El proceso de investigación; enfoque cualitativo. Bucaramanga, módulo primer semestre académico Maestría en Pedagogía, 2009.

VARGAS, Alberto. (2004) Estándares y ética de la comunicación. En En Redate Vé. Boletín No. 7. Enero de 2004. Universidad del Valle- Red de Maestros del Valle del Cauca para la Transformación de la Cultura Escolar desde el Lenguaje. Cali.

VILCHES, Lorenzo. La imagen es un texto. La lectura de la imagen. Paidos: México, 1991.

WOODS, Peter. La escuela por dentro. La etnografía en la investigación educativa. Ediciones Paidós Madrid, 1986. 